\title{
The renoprotective effect and safety of a DPP-4 inhibitor, sitagliptin, at a small dose in type 2 diabetic patients with a renal dysfunction when changed from other DPP-4 inhibitors: REAL trial
}

\author{
Koichi Kanozawa ${ }^{1} \cdot$ Yuichi Noguchi $^{2} \cdot$ Souichi Sugahara $^{3} \cdot$ Satoko Nakamura $^{4} \cdot$ Hirohisa Yamamoto $^{5} \cdot$ Keiko Kaneko $^{6}$. \\ Rika Kono $^{7}$. Saeko Sato ${ }^{1} \cdot$ Tomonari Ogawa $^{1} \cdot$ Hajime Hasegawa $^{1} \cdot$ Shigehiro Katayama $^{8}$
}

Received: 20 August 2017 / Accepted: 6 December 2017 / Published online: 23 December 2017

(c) The Author(s) 2017. This article is an open access publication

\begin{abstract}
Background We conducted the multicenter, prospective, open-label study in type 2 diabetic (T2DM) patients with renal dysfunction, to clarify the efficacy and the safety in relation to renal function and glycemic control, and the economic effect when other dipeptidyl peptidase-4 (DPP-4) inhibitors were switched to a small dose of sitagliptin depending on their renal function.

Methods Vildagliptin, alogliptin, or linagliptin received for more than 2 months were changed to sitagliptin at $25 \mathrm{or} 12.5 \mathrm{mg} /$ day depending on their renal function in 49 T2DMs. Renal function and glycemic control, and the drug cost were assessed during 6 months.

Results Estimated glomerular filtration rate was not changed in patients not on hemodialysis $(n=29)$. The HbA1c levels were not altered in all of the patients including those on hemodialysis $(n=20)$. The active glucagon-like peptide-1 levels or other renal parameters were not altered significantly. There were no adverse events to be related to the drugs. The daily drug expense was reduced by 88.1 yen per patient.

Conclusion Switching to a small dose of sitagliptin according to the renal function in T2DM patients with renal dysfunction demonstrated the same efficacy and safety as those with other full-dose DPP-4 inhibitors, indicating a therapeutic option with a high cost performance.
\end{abstract}

Keywords Sitagliptin · DPP-4 inhibitor · CKD $\cdot$ Type 2 diabetes mellitus $\cdot$ Cost benefit

\section{Introduction}

In Japan, an investigation conducted by the Japanese Society for Dialysis Therapy showed that the number of patients on

Electronic supplementary material The online version of this article (https://doi.org/10.1007/s10157-017-1521-7) contains supplementary material, which is available to authorized users.

\section{Koichi Kanozawa}

kanozawa@saitama-med.ac.jp

1 Division of Nephrology and Hypertension, Blood Purification Center, Saitama Medical Center, Saitama Medical University, 1981, Kamoda, Kawagoe, Saitama 350-8550, Japan

2 Department of Endocrinology and Diabetes, Saitama Medical University, 38, Morohongo, Moroyama-machi Iruma-gun, Saitama 350-0451, Japan

3 Shingashi Kidney Centre, 39-1, Shimoshingashi, Kawagoe-shi, Saitama 350-1136, Japan dialysis was 324,986 at the end of 2015 , which increased by 4,538 from the previous year [1]. The number indicates that

4 Sekishin Health Care Clinic, 25-18, Wakita Honcho, Kawagoe-shi, Saitama 350-1123, Japan

5 Kawagoe Ekimae Clinic, Ishikawa Kinenkai Medical Group, Kawagoe Ekimae Bld. 2F, 16-23, Wakita Honcho, Kawagoe-shi, Saitama 350-1123, Japan

6 Higashi-Hannou Ekimae Clinic, Takahasi Bld.2, 3F, 3-5, Yanagicho, Hanno-shi, Saitama 357-0035, Japan

7 Iruma Ekimae Clinic, Yokota Square Bld.4, 5F, 1-2-30, Toyooka, Iruma-shi, Saitama 358-0003, Japan

8 Kawagoe Clinic, Saitama Medical University, 21-7 Wakita Honcho, Kawagoe-shi, Saitama 350-1123, Japan 
1 out of approximately 450 people in Japan is on dialysis, the incidence of which is largest in the world [2]. This fact has a critical effect not only on the issues of patients' life prognosis or their quality of life but also on economic issues with regard to medical expenses. The total annual cost of dialysis therapy throughout the country is approximately 1.5 trillion yen, i.e., those patients, $0.2 \%$ of population, expense $4 \%$ of total medical costs. Among the causative diseases that lead to dialysis initiation, diabetic nephropathy ranks the first at $43.7 \%$; thus, reducing the medical costs in diabetic nephropathy should be a priority [1].

The route of excretion of DPP-4 inhibitors varies depending on the drug; sitagliptin, alogliptin, anagliptin, omarigliptin, and trelagliptin are mainly excreted as unmetabolized drugs from the kidney into the urine. Vildagliptin and saxagliptin are metabolized mainly in the liver. Linagliptin is excreted through the biliary system, and teneligliptin is metabolized in the liver and excreted from renal systems. Based on these differences, the appropriate doses depending on the renal function vary among drugs. The dosage of sitagliptin can be adjusted based on the degree of renal impairment. However, the efficacy and safety of sitagliptin at a smaller dose are less recognized.

Although there are some reports comparing the hypoglycemic effect of the different classes of DPP-4 inhibitors in patients with type 2 diabetes mellitus (T2DM) [3-6], efficacy of different DPP-4 inhibitors on glycemic control was not the same from one report to another. Furthermore, serum levels of active glucagon-like peptide-1 (aGLP-1), or C-peptide, which are the direct or indirect targets of DPP-4 inhibitor, have not been reported. In addition, there are a few reports comparing the efficacy and safety of sitagliptin with other DPP-4 inhibitors [7, 8] and no reports that compare the efficacy and the safety of a smaller dosage of sitagliptin adjusted in accordance with their renal function with those of other DPP-4 inhibitors in patients with renal impairment.

Thus, in this study, we evaluated the effectiveness and safety in relation to renal function and glycemic control of switching from other DPP-4 inhibitors to a smaller dose sitagliptin in patients with impaired renal function. Furthermore, changes in daily drug cost were also examined.

\section{Methods}

\section{Study design}

An open-label, central registration, prospective, non-randomized and pragmatic intervention study, The renal effect and safety of sitagliptin (REAL) trial, was conducted in seven facilities including Saitama Medical University Hospital and Saitama Medical Center. Patients were enrolled from April 1, 2014, to December 31, 2015, with the follow-up period until June 30, 2016. This study was conducted in compliance with the protocol, the Helsinki Declaration, and the "ethical guidelines for clinical studies" by the Ministry of Health, Labour, and Welfare. The study was approved by the ethical committee of Saitama Medical University Hospital (on December 10, 2013; result notification number, 13-094-1; UMIN000016072). It was funded by the Waksman Foundation.

\section{Study participants}

The study participants were those who met the following inclusion criteria: (1) Japanese T2DM patients; (2) those who had moderate or severe renal impairment [estimated glomerular filtration rate (eGFR) less than $60 \mathrm{~mL} /$ $\min / 1.73 \mathrm{~m}^{2}$, including those who had severe renal impairment/end-stage renal disease]; (3) those who had been treated with hypoglycemic drugs, including vildagliptin, alogliptin, and linagliptin, which were approved in a relatively early phase in Japan, for more than 2 months; (4) those who had $\mathrm{HbAlc}$ greater than $6.0 \%$ but less than $9.0 \%$; and (5) those who provided written consent.

Additionally, those falling under the following conditions were excluded: (1) patients with a history of severe ketosis, diabetic coma, or previous coma in the past 6 months; (2) those with severe infection, in pre- or post-operative state, and with serious trauma; (3) pregnant women, possibly pregnant, and breastfeeding; (4) those who had been prescribed biguanide, glinide, or GLP-1 receptor analog; (5) those with a history of hypersensitivity to any ingredient of the study drug; and (6) those who were considered unsuitable to participate in the study based on medical evidence observed by the attending physician.

\section{Treatments}

Hypoglycemic drugs including vildagliptin, alogliptin, or linagliptin had been administered to the T2DM patients with moderate or severe renal impairment for more than 2 months to treat diabetes mellitus. As shown in Fig. 1, these DPP-4 inhibitors were changed to sitagliptin after obtaining a written consent to participate in the study. The chosen doses of sitagliptin were $25 \mathrm{mg} /$ day in cases with eGFR of greater than $30 \mathrm{~mL} / \mathrm{min} / 1.73 \mathrm{~m}^{2}$ and less than $60 \mathrm{~mL} / \mathrm{min} / 1.73 \mathrm{~m}^{2}$ and $12.5 \mathrm{mg} /$ day in cases with eGFR of less than $30 \mathrm{~mL} /$ $\mathrm{min} / 1.73 \mathrm{~m}^{2}$. After initiating the study, the above mentioned drug should be continuously administered for a month and must not be changed. If the target of glycemic control in HbA1c of less than $7.0 \%$ could not be achieved after the second month, sitagliptin dosage can be increased. If the targeted plasma glucose levels could not be achieved even after the third month, other hypoglycemic drugs (sulfonylurea, alpha-glucosidase inhibitor, thiazolidine, or insulin) 
Fig. 1 Study design

Other antidiabetic drugs can be added

Ineffective cases: sitagliptin can be increased to $50 \mathrm{mg}$

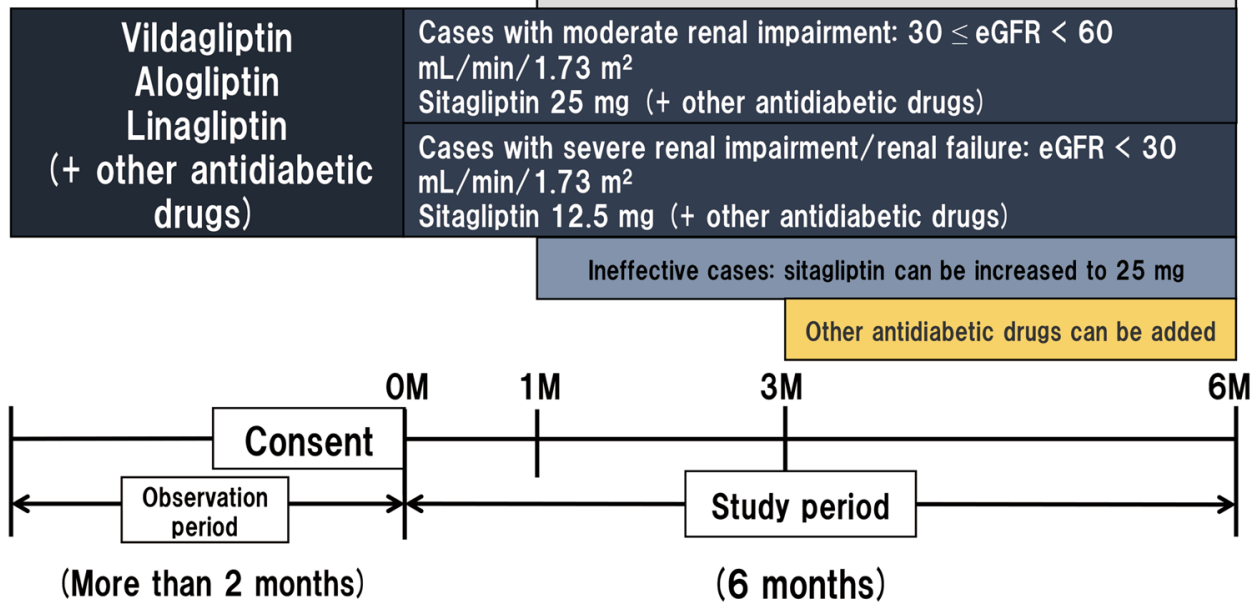

can be added. Although administration of treatment drugs for complications was not limited, dose changes or new drug additions were minimized as much as possible. Blood and urine were collected before 3 and 6 months and after the initiation of the study for the laboratory tests including some special biomarkers as well as the usual blood chemistry. Additional blood samples were collected to determine plasma glucose and $\mathrm{HbA} 1 \mathrm{c}$ levels to adjust the dosage of sitagliptin 1 month after the initiation of the study. For the determination of plasma aGLP-1 levels, which consist of GLP-1 (7-36) amide and GLP-1 (7-37), blood sample was collected into a tube containing DPP-4 inhibitor followed by a solid phase extraction and the extract was utilized to measure the plasma aGLP-1 level using the ELISA method [9]. To accurately measure the postprandial levels of C-peptide, aGLP-1, or triglyceride (TG), blood samples were ideally collected an hour after meals, but samples collected up to $2 \mathrm{~h}$ after meals were still considered acceptable.

\section{Evaluation}

The primary endpoints were changes in the markers of renal function (creatinine, cystatin C, eGFR, and eGFRcys) in subjects before the initiation of dialysis.

The secondary end points were changes in the following: body weight, BMI, systolic blood pressure (SBP) and diastolic blood pressure (DBP), HbA1c, postprandial plasma glucose, LDL-cholesterol (C), TG, HDL-C, aGLP-1, and C-peptide. Especially, whether or not glycemic control was affected after switching to a small dose of sitagliptin from other DPP-4 inhibitors before the study was evaluated in all patients and separately in two groups of patients, i.e., not on dialysis and on dialysis. In addition, urinary albumin-to-creatinine ratio (UACR), and the markers of cardiac and renal function were determined. Biomarkers determined were serum levels of atrial natriuretic hormone (ANP), NT-probrain natriuretic hormone (BNP), pentraxin 3 (PTX-3), highsensitive C-reactive protein (hs-CRP) and urinary levels of liver-type fatty acid binding protein (L-FABP), collagen type IV, 8 -isoprostane, and $\beta 2$-microglobulin. Additionally, the drug prices before and after switching the drugs were also compared based on the 2016 price list. The prescription cost of sitagliptin $12.5 \mathrm{mg}$ was calculated based on the half price of sitagliptin $25 \mathrm{mg}$ tablet. When measuring HbA1c was difficult in dialysis patients, the value of glycated albumin was divided by 3.57 , which was based on data of Japanese hemodialysis patients with T2DM, described by Inaba et al. [10].

\section{Statistical analysis}

We analyzed all the data from the whole participants and further analyses were done separately in two groups, i.e., patients not on hemodialysis and on hemodialysis. The subject population for analysis was all the data according to intention to treat (ITT). The values of the continuous variables are shown as the mean \pm SD or median (1st quantile, 3rd quantile), while categorical variables are shown as the number or percent. The changes from the baseline were analyzed using a one-way analysis of variance (ANOVA) for parametric continuous variables with equal variance and then by Bonferroni's multiple comparisons as a post hoc test. Non-parametric continuous variables without equal variance were analyzed using the Friedman test. Missing values were imputed using the last observation carried forward method. The statistical analyses were performed using the $\mathrm{R}$ version 3.4.0 (R Foundation for statistical Computing, Vienna, Austria). $P$ values of $<0.05$ were considered to indicate statistical significance. 


\section{Results}

All cases were analyzed for efficacy and safety based on the ITT, with the patients' backgrounds shown in Table 1. A total of 49 patients were enrolled in this study. The mean age was $69.9 \pm 9.4$ years, and the proportion of male was $65.3 \%$. Patients were classified into two groups: 29 patients not on hemodialysis (with an average dose of sitagliptin $23.7 \pm 5.6 \mathrm{mg}$ ) and 20 patients on hemodialysis (with an average dose of sitagliptin $12.8 \pm 2.0 \mathrm{mg}$ ). Biguanide was used in 5 patients with moderate renal dysfunction, but they did not have any adverse events such as lactic acidosis.

In all of the patients, the levels of HbAlc and postprandial plasma glucose were not significantly changed after switching the DPP-4 inhibitors before the study as shown in Table 2. Serum levels of C-peptide and aGLP-1 were also the same before and after switching the drug. SBP, DBP and serum lipid levels were not significantly changed. Table 2 also shows the data separately in patients not on hemodialysis and on hemodialysis. Serum levels of creatinine and cystatin $\mathrm{C}$ were not altered during 6-month study period both in those not on hemodialysis and on hemodialysis.

Table 1 Patients' backgrounds $(n=49)$

\begin{tabular}{ll}
\hline Age (years) & $69.9 \pm 9.4$ \\
Sex & \\
Men & $32(65.3 \%)$ \\
Women & $17(34.7 \%)$ \\
Duration of diabetes & \\
Less than 1 year & $1(2.0 \%)$ \\
More than 1 year and less than 5 years & $3(6.1 \%)$ \\
More than 5 years and less than 10 years & $6(12.2 \%)$ \\
More than 10 years & $37(75.5 \%)$ \\
Unknown & $2(4.1 \%)$ \\
Complications & \\
Diabetic retinopathy & $17(34.7 \%)$ \\
Diabetic neuropathy & $8(16.3 \%)$ \\
Hypertension & $43(87.8 \%)$ \\
Dyslipidemia & $25(51.0 \%)$ \\
Hyperuricemia & $19(38.8 \%)$ \\
Liver disease & $23(46.9 \%)$ \\
Hemodialysis & $20(40.8 \%)$ \\
Antidiabetic drugs & \\
Combined use of antidiabetic drugs other than the & $24(49.0 \%)$ \\
study drugs & $7(14.3 \%)$ \\
SU & $12(24.5 \%)$ \\
a-GI & $0(0 \%)$ \\
TZD & $5(10.2 \%)$ \\
BG Insulin & $5(10.2 \%)$ \\
\hline &
\end{tabular}

Data are $n(\%)$ or means \pm SD
Other parameters were almost the same before and after the study in both groups except a significant decrease in SBP at 6 months in patients not on hemodialysis.

Other changes in various parameters determined during the study are also indicated in Table 2. Although serum levels of NT-proBNP, ANP, PTX3, and hs-CRP tended to be higher in patients on hemodialysis compared to those in patients not on hemodialysis, they did not show any significant change between the baseline and the end of the study in each group except a slight, but significant, increase in ANP levels after 6 months in all patients or in patients on hemodialysis.

Table 3 shows eGFR and eGFRcys, and urinary parameters determined in those not on hemodialysis. eGFR as well as eGFRcys did not differ between the baseline and the end of the study. Please note that the eGFR in non-dialysis patients was $43.5 \pm 14.9 \mathrm{~mL} / \mathrm{min} / 1.73 \mathrm{~m}^{2}$ at baseline and $42.6 \pm 14.4 \mathrm{~mL} / \mathrm{min} / 1.73 \mathrm{~m}^{2}$ after 6 months. Among the parameters related to renal function, no significant changes were noted in UACR and urinary excretion of $\beta 2$-microglobulin, collagen IV, L-FABP and 8-isoprostane.

The patients were classified based on DPP-4 inhibitors utilized before the study (Table S1). As shown in Table S2, there were no significant differences in $\mathrm{HbA1c}$, and eGFR and eGFRcys in each group according to the drug before the study. Please note that vildagliptin administered before the study was $100 \mathrm{mg} /$ day in 14 patients, the dosage of which might not be recommended for patients with moderate to severe renal impairment including patients on hemodialysis because of the increase in serum concentrations of vildagliptin.

As illustrated in Fig. 2, after changing the drugs, the daily drug cost per patient was significantly reduced by 88.1 yen from $143.9 \pm 40.5$ to $55.8 \pm 18.7$ yen, which might be estimated to be a cost reduction of 32,157 yen per year.

The adverse events reported were death, dizziness, bradycardia-tachycardia syndrome, and paroxysmal atrial fibrillation. Each of them occurred only once and was not suspected to be related to the study drugs. The death occurred 1 month after the study, and this patient had a history of myocardial infarction.

\section{Discussion}

In the present study, we included T2DM cases with moderate or severe renal impairment and, according to the degree of the renal dysfunction, changed their therapeutic drug to a small dose of sitagliptin from other DPP-4 inhibitors to determine its efficacy and safety in relation to renal function and glycemic control. No significant changes were observed in the parameters related to renal function as well 
Table 2 Vital and serum parameters determined before and during the study

\begin{tabular}{|c|c|c|c|c|c|c|c|c|c|}
\hline \multirow[t]{2}{*}{ Parameters } & \multicolumn{3}{|c|}{ All patients $(n=49)$} & \multicolumn{3}{|c|}{ Patients not on hemodialysis $(n=29)$} & \multicolumn{3}{|c|}{ Patients on hemodialysis $(n=20)$} \\
\hline & $0 \mathrm{M}$ & $3 \mathrm{M}$ & $6 \mathrm{M}$ & $0 \mathrm{M}$ & $3 \mathrm{M}$ & $6 \mathrm{M}$ & $0 \mathrm{M}$ & $3 \mathrm{M}$ & $6 \mathrm{M}$ \\
\hline $\begin{array}{l}\text { SBP } \\
\quad(\mathrm{mmHg})\end{array}$ & $138.9 \pm 20.2$ & $143.4 \pm 21.1$ & $138.4 \pm 21.5$ & $130.5 \pm 10.2$ & $129.9 \pm 9.17$ & $125.6 \pm 9.52 *$ & $151.5 \pm 24.7$ & $163.0 \pm 17.7$ & $157.1 \pm 20.4$ \\
\hline $\begin{array}{l}\mathrm{DBP} \\
\quad(\mathrm{mmHg})\end{array}$ & $75.9 \pm 12.8$ & $77.6 \pm 15.0$ & $76.1 \pm 13.6$ & $73.6 \pm 11.5$ & $71.3 \pm 11.4$ & $72.3 \pm 11.1$ & $79.3 \pm 14.1$ & $86.7 \pm 15.1$ & $81.5 \pm 15.3$ \\
\hline $\begin{array}{l}\text { Pulse rate } \\
\text { (betas/ } \\
\text { min) }\end{array}$ & $73.1 \pm 10.6$ & $74.9 \pm 10.9$ & $74.7 \pm 11.6$ & $71.0 \pm 10.1$ & $73.0 \pm 11.2$ & $72.9 \pm 12.3$ & $76.2 \pm 10.9$ & $77.7 \pm 10.3$ & $77.3 \pm 10.3$ \\
\hline $\begin{array}{l}\text { Body weight } \\
(\mathrm{kg})\end{array}$ & $61.5 \pm 10.6$ & $61.6 \pm 10.6$ & $61.8 \pm 10.6$ & $62.3 \pm 10.9$ & $62.3 \pm 10.7$ & $62.7 \pm 10.9$ & $60.9 \pm 10.5$ & $61.0 \pm 10.8$ & $61.1 \pm 10.5$ \\
\hline $\begin{array}{l}\mathrm{BMI}(\mathrm{kg} / \\
\left.\mathrm{m}^{2}\right)\end{array}$ & $23.9 \pm 3.2$ & $23.9 \pm 3.2$ & $24.0 \pm 3.3$ & $25.0 \pm 3.02$ & $25.1 \pm 2.91$ & $25.2 \pm 3.03$ & $22.9 \pm 3.03$ & $22.9 \pm 3.15$ & $23.0 \pm 3.19$ \\
\hline HbA1c $(\%)$ & $6.30 \pm 0.75$ & $6.44 \pm 0.90$ & $6.40 \pm 0.81$ & $6.63 \pm 0.56$ & $6.70 \pm 0.62$ & $6.67 \pm 0.58$ & $5.81 \pm 0.73$ & $6.07 \pm 1.12$ & $6.01 \pm 0.96$ \\
\hline $\begin{array}{l}\text { Plasma } \\
\text { glucose } \\
\text { (mg/dL) }\end{array}$ & $152.6 \pm 46.9$ & $150.3 \pm 47.0$ & $153.4 \pm 49.8$ & $156.1 \pm 42.4$ & $150.1 \pm 38.1$ & $161.1 \pm 47.1$ & $147.5 \pm 53.5$ & $150.7 \pm 58.6$ & $142.3 \pm 52.7$ \\
\hline $\begin{array}{r}\text { C-peptide } \\
\text { (ng/mL) }\end{array}$ & $\begin{array}{c}5.89(4) \\
7.82)\end{array}$ & $\begin{array}{l}6.42(4.01, \\
8.72)\end{array}$ & $\begin{array}{l}6.17(4.28, \\
8.45)\end{array}$ & $\begin{array}{l}5.2(3.09, \\
7.17)\end{array}$ & $\begin{array}{l}5.17(3.59, \\
7.09)\end{array}$ & $\begin{array}{c}4.86(3.5, \\
6.79)\end{array}$ & $\begin{array}{c}7.61(5.2 \\
10.48)\end{array}$ & $\begin{array}{l}8.38(5.34 \\
11.25)\end{array}$ & $\begin{array}{c}8.36(6.18, \\
10.35)\end{array}$ \\
\hline $\begin{array}{l}\mathrm{aGLP}-1 \\
\quad(\mathrm{pmol} / \mathrm{L})\end{array}$ & $\begin{array}{c}7.3(4.88, \\
10.15)\end{array}$ & $\begin{array}{r}5.7(3.5 \\
11.65)\end{array}$ & $\begin{array}{l}6.75(3.73, \\
10)\end{array}$ & $\begin{array}{c}7.2(4.8 \\
8.48)\end{array}$ & $\begin{array}{l}5.5(3.28 \\
9.03)\end{array}$ & $\begin{array}{l}6.1(2.98, \\
8.48)\end{array}$ & $\begin{array}{c}8.15(5.23, \\
15.95)\end{array}$ & $\begin{array}{c}9.4(3.85 \\
19.63)\end{array}$ & $\begin{array}{c}7.6(3.95 \\
13.1)\end{array}$ \\
\hline $\begin{array}{l}\text { Triglyceride } \\
\text { (mg/dL) }\end{array}$ & $142.4 \pm 89.8$ & $145.6 \pm 87.7$ & $137.0 \pm 76.0$ & $164.2 \pm 95.3$ & $161.1 \pm 93.9$ & $160.8 \pm 83.9$ & $122.8 \pm 82.0$ & $131.7 \pm 81.5$ & $115.6 \pm 62.7$ \\
\hline $\begin{array}{l}\text { LDL-C (mg/ } \\
\text { dL) }\end{array}$ & $87.9 \pm 27.5$ & $85.9 \pm 24.7$ & $87.6 \pm 26.5$ & $96.3 \pm 24.0$ & $92.7 \pm 19.9$ & $97.3 \pm 21.0$ & $80.3 \pm 28.9$ & $79.8 \pm 27.4$ & $78.8 \pm 29.2$ \\
\hline $\begin{array}{l}\text { HDL-C } \\
\quad(\mathrm{mg} / \mathrm{dL})\end{array}$ & $43.4 \pm 13.5$ & $44.2 \pm 13.1$ & $45.2 \pm 12.7$ & $41.9 \pm 13.3$ & $43.9 \pm 14.1$ & $45.2 \pm 13.7$ & $44.7 \pm 13.9$ & $44.5 \pm 12.6$ & $45.2 \pm 12.1$ \\
\hline $\begin{array}{r}\text { creatinine } \\
(\mathrm{mg} / \mathrm{dL})\end{array}$ & $4.48 \pm 4.20$ & $4.65 \pm 4.20 *$ & $4.73 \pm 4.40^{*}$ & $1.31 \pm 0.55$ & $1.33 \pm 0.59$ & $1.34 \pm 0.61$ & $9.07 \pm 2.57$ & $9.48 \pm 2.39$ & $9.64 \pm 2.37$ \\
\hline $\begin{array}{c}\text { cystatin C } \\
(\mathrm{mg} / \mathrm{L})\end{array}$ & $3.75 \pm 2.71$ & $3.82 \pm 4.34$ & $3.84 \pm 2.82$ & $1.62 \pm 0.70$ & $1.62 \pm 0.73$ & $1.62 \pm 0.76$ & $6.74 \pm 1.15$ & $6.89 \pm 1.17$ & $6.95 \pm 1.21$ \\
\hline $\begin{array}{l}\text { NT-ProBNP } \\
(\mathrm{pg} / \mathrm{mL})\end{array}$ & $\begin{array}{c}405(68.3 \\
4317.5)\end{array}$ & $\begin{array}{c}413.5(67.5 \\
4207.5)\end{array}$ & $\begin{array}{c}585(59) \\
4200)\end{array}$ & $\begin{array}{c}83.5(55.3 \\
242.5)\end{array}$ & $\begin{array}{c}74(54.5 \\
278.8)\end{array}$ & $\begin{array}{c}71.5(45.5 \\
271.8)\end{array}$ & $\begin{array}{c}5975(2555 \\
29,600)\end{array}$ & $\begin{array}{l}5275 \\
(3042.5, \\
16,675)\end{array}$ & $\begin{array}{c}5510(2387.5 \\
14,700)\end{array}$ \\
\hline $\begin{array}{l}\mathrm{ANP}(\mathrm{pg} / \\
\mathrm{mL})\end{array}$ & $\begin{array}{c}56(23.1 \\
168.3)\end{array}$ & $\begin{array}{l}58.1(24.3 \\
211.5)\end{array}$ & $\begin{array}{c}71.1(28.4, \\
207.8)\end{array}$ & $\begin{array}{l}26.7(17.4, \\
53.9)\end{array}$ & $\begin{array}{c}25.5(22 \\
47.3)\end{array}$ & $\begin{array}{l}31.4(22.2, \\
57)\end{array}$ & $\begin{array}{c}195(100.1, \\
311.5)\end{array}$ & $\begin{array}{c}245(99.8 \\
396.8)\end{array}$ & $\begin{array}{l}232.5(134.8 \\
363)\end{array}$ \\
\hline $\begin{array}{l}\text { PTX3 (ng/ } \\
\text { mL) }\end{array}$ & $\begin{array}{l}2.14(1.45, \\
4.05)\end{array}$ & $\begin{array}{l}2.01(1.41, \\
3.65)\end{array}$ & $\begin{array}{l}2.27(1.37, \\
3.36)\end{array}$ & $\begin{array}{c}1.54(1.1, \\
1.89)\end{array}$ & $\begin{array}{l}1.63(1.1, \\
1.9)\end{array}$ & $\begin{array}{l}1.61(1.13, \\
2.27)\end{array}$ & $\begin{array}{l}4.23(3.1 \\
5.25)\end{array}$ & $\begin{array}{l}3.92(3.17 \\
5.27)\end{array}$ & $\begin{array}{c}3.69(2.5 \\
5.13)\end{array}$ \\
\hline $\begin{array}{l}\text { hs-CRP (ng/ } \\
\text { mL) }\end{array}$ & $\begin{array}{c}790.5(326 \\
1852.5)\end{array}$ & $\begin{array}{l}661(278.5 \\
2035)\end{array}$ & $\begin{array}{c}917.5 \\
\quad(366.8 \\
2420)\end{array}$ & $\begin{array}{c}659(341.5 \\
1260)\end{array}$ & $\begin{array}{c}661(294.8 \\
1880)\end{array}$ & $\begin{array}{c}762(307.3 \\
2362.5)\end{array}$ & $\begin{array}{l}1210 \\
(193.3, \\
3662.5)\end{array}$ & $\begin{array}{l}846.5 \\
(278.5, \\
2772.5)\end{array}$ & $\begin{array}{c}1068(469 \\
2472.5)\end{array}$ \\
\hline
\end{tabular}

Data are means \pm SD or median (1st quantile, 3rd quantile). Parametric test: SBP, DBP, pulse rate, body weight, BMI, HbA1c, plasma glucose, triglyceride, LDL-C, HDL-C, creatinine, cystatin C. Non-parametric test: C-peptide, aGLP-1, NT-ProBNP, ANP, PTX3, hs-CRP

$* p<0.05$ vs. $0 \mathrm{M}$ (repeated ANOVA with Bonferroni correction)

${ }^{\dagger} p<0.05$ vs. $0 \mathrm{M}$ (Friedman test with Bonferroni correction)

as glycemic control. No adverse events caused by the study drug were noted.

With regard to glycemic control, HbAlc levels were not significantly altered after switching to a small dose of sitagliptin from other DPP-4 inhibitors at the full-dose before the study not only in the overall analysis but also in the separate analysis of the patients not on hemodialysis and patients on hemodialysis. The results were almost the same when separated by DPP-4 inhibitors used before the study although the number of patients on alogliptin was not enough for a definite conclusion. When comparing the glycemic control in patients with severe renal impairment taking sitagliptin and other DPP-4 inhibitors, Kothny et al. [8] reported that sitagliptin and vildagliptin have a similar efficacy. However, Park et al. [9] reported that sitagliptin showed a much higher efficacy compared to that of vildagliptin and linagliptin. In 
Table 3 Renal parameters in patients not on hemodialysis $(n=29)$

\begin{tabular}{llll}
\hline Parameters & $0 \mathrm{M}$ & $3 \mathrm{M}$ & $6 \mathrm{M}$ \\
\hline eGFR $\left(\mathrm{mL} / \mathrm{min} / 1.73 \mathrm{~m}^{2}\right)$ & $43.5 \pm 14.9$ & $43.8 \pm 16.6$ & $42.6 \pm 14.4$ \\
eGFRcys $(\mathrm{mL} / \mathrm{min} / 1.73 \mathrm{~m} 2)$ & $60.5 \pm 24.6$ & $60.6 \pm 24.2$ & $61.3 \pm 25.5$ \\
UACR $(\mathrm{mg} / \mathrm{gCr})$ & $17.4(4.8,62.4)$ & $22.9(8.8,51.7)$ & $21.2(9.2,118.5)$ \\
Urinary $\beta 2$-microglobulin $(\mu \mathrm{g} / \mathrm{gCr})$ & $166(58.8,580.5)$ & $228.5(84,1217.3)$ & $505(71,1550)$ \\
Urinary collagen IV $(\mu \mathrm{g} / \mathrm{gCr})$ & $4.5(3.03,9.85)$ & $5.55(3.23,11.25)$ & $6.5(2.68,9.85)$ \\
L-FABP $(\mu \mathrm{g} / \mathrm{gCr})$ & $5.2(3.4,24.3)$ & $5.5(2.7,14.7)$ & $5.1(2.8,16.8)$ \\
U-8 isoprotane $(\mathrm{pg} / \mathrm{mgCr})$ & $208(125,279.8)$ & $160.5(126.5,214)$ & $193.5(114.5,268.5)$
\end{tabular}

Data are means \pm SD or median (1st quantile, 3rd quantile)

Changes in eGFR and eGFRcys were not statistically significant during the study by repeated ANOVA

Changes in UACR, Urinary $\beta 2$-microglobulin, Urinary collagen IV, L-FABP, and U-8 isoprotane were not statistically significant during the study by Friedman test

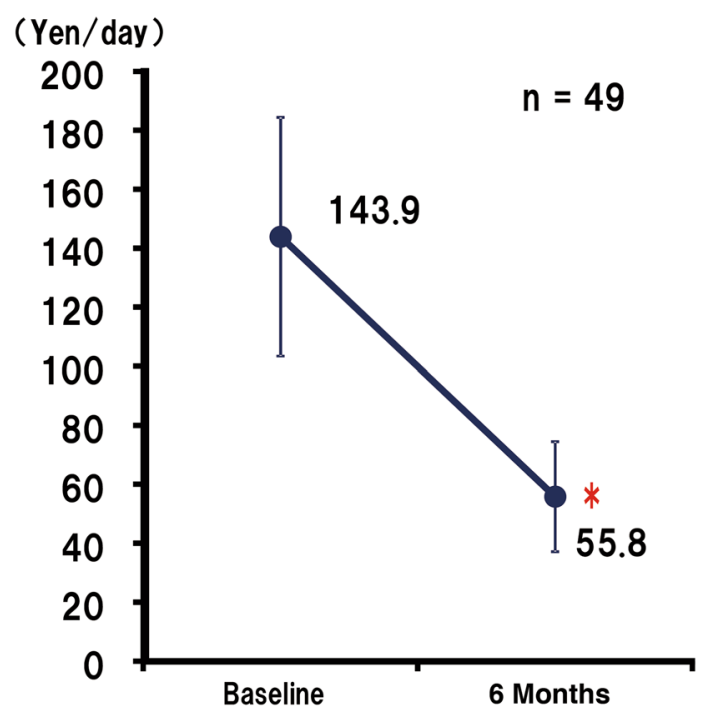

Fig. 2 Daily drug cost. ${ }^{*} p<0.05$ vs. $0 \mathrm{M}$ (paired $t$ test)

treating T2DM patients with stages 3 to 5 chronic kidney disease (CKD) including those with end-stage renal disease, sitagliptin has been reported to be effective in controlling plasma glucose levels and maintaining the safety [11-13]. However, these reports only discussed the plasma glucose control mainly by measuring $\mathrm{HbAlc}$, and the targets of DPP-4 inhibitors to achieve good glycemic control, such as aGLP-1, have not been discussed. In the present study, even after changing to a small dosage of sitagliptin based on their renal function, serum levels of aGLP-1 and C-peptide were not altered when compared to those on other DPP-4 inhibitors almost at the full-dose before the study.

In relation to renal function, the effect of sitagliptin has been discussed in several reports. In a Japanese report on patients with normal renal function, the serum creatinine concentration slightly, but significantly, increased 1 month after administering sitagliptin, showing no significant difference after 24 months compared to 6 months [14]. The sub-analysis of the Trial Evaluating Cardiovascular Outcomes with Sitagliptin study (TECOS) to evaluate cardiovascular outcome in mainly normoalbuminuric T2DM patients receiving sitagliptin showed that mean change of eGFR during 48 months from the baseline was significantly lower in the sitagliptin group than in the placebo group, but the cumulative incidence of microalbuminuria and renal failure was equivalent in two groups [15]. The efficacy and safety of sitagliptin had also been reported in patients with renal failure [11-13]. Taking these reports together into consideration, subtle changes in renal function caused by sitagliptin might be generally safe. However, no detailed studies exist that directly compared the indexes relating to renal function between sitagliptin and other DPP-4 inhibitors, therefore, we have set the influence on renal function in parallel with the effect on glycemic control as the endpoint for patients with renal dysfunction, including dialysis patients. In the present study, no significant changes in eGFR were found after switching to sitagliptin from other DPP-4 inhibitors administered before the study. Albuminuria in Japanese T2DM patients has been regarded to be the risk of cardiovascular events, as well as the risk of renal events such as overt nephropathy, eGFR decrease of more than $50 \%$, dialysis and renal transplantation [16, 17]. In the present study, UACR was not altered after switching DPP-4 inhibitors before the study to a small dose of sitagliptin according to their renal dysfunction. In addition, we determined various serum and urinary biomarkers reflecting deterioration of renal function and occurrence of cardiovascular disease such as collagen type IV, L-FABP, and PTX-3. Urinary excretion of collagen type IV, a component of the renal glomerular basement membrane, is increased along with progression of diabetic nephropathy [18]. Increased L-FABP levels have been reported to be the risk not only of decreased eGFR by more than $50 \%$ or progression to stage $4 \mathrm{CKD}$, but also cardiovascular disease [17]. PTX-3 is an excellent inflammation marker of human diabetic nephropathy originating from the blood vessels, which correlates with proteinuria 
and is independent of eGFR [19]. In the present study, no significant changes have been noted in the various biomarkers as mentioned above after changing the drugs. There were no adverse events that were related to the study drug. These results demonstrated, for the first time, that switching to a small dose of sitagliptin based on the renal function has been demonstrated to be effective and safe when administered to the T2DM patients with moderate to severe renal dysfunction.

The renal excretion rates as unchanged sitagliptin, alogliptin, vildagliptin, and linagliptin were reported to be $80,60-71,21$, and $<6 \%$, respectively, showing a higher excretion rate of sitagliptin in the urine compared to any other DPP-4 inhibitors [20]. The concentration of sitagliptin at a decreased dose depending on the degree of renal dysfunction in the tubular lumen was unknown. However, since no changes in the degree of the glycemic control, renal function, or other renal markers were noted, the same degree of efficacy and safety was observed at a small dose of sitagliptin depending on the degree of renal dysfunction, suggesting that, facing to an impaired renal function, a small dose of sitagliptin actually works to the same degree as a full-dose sitagliptin or other DPP-4 inhibitors under a normal renal function.

In recent years, many studies have been reported that DPP-4 inhibitors have renoprotective action. GLP-1 has been reported to have various renoprotective effects [21-31], but renal expression of GLP-1 is suppressed in T2DM [32]. Sitagliptin elevates downregulated intrarenal GLP-1 expression in the T2DM rat model [32]. In addition, DPP-4 has been elucidated to degrade many peptides such as glucagon-like peptide-2 (GLP-2), BNP, ANP, stromal cell-derived factor (SDF)-1 $\alpha$, substance $\mathrm{P}$, neuropeptide Y, peptide YY, and so on. Activation and prolongation of their physiological activities by DPP-4 inhibition can lead to actions such as natriuresis, improvement of inflammation, suppression of the sympathetic nervous activity, suppression of the renin-angiotensin system, vasodilatation, and cytoprotection [33, 34]. Natriuresis has been reported to occur by DPP-4 inhibitor independent of GLP-1 receptor [24] because DPP-4 inhibitors have directly reduced the expression of sodium-proton exchanger 3 (NHE3) protein [35], and promoted a distal tubular natriuresis through SDF-1 $\alpha$ [36]. Furthermore, DPP-4 inhibitors may enhance the secretion of BNP or ANP from the atrium, resulting in natriuresis [37]. In T2DM animal models such as Zucker diabetic fatty rats [32], sitagliptin has been reported to suppress the inflammatory cytokines and apoptosis, resulting in an improvement of glomerular and tubular atrophies. Furthermore, in streptozotocin-induced diabetic rats, linagliptin suppressed enhanced DPP-4 activity and ameliorated kidney fibrosis [38]. Taking these results together into consideration, sitagliptin may have an anti-inflammatory, anti-fibrotic, and anti-oxidative action, in addition to natriuretic action, resulting in renoprotection.

In fact, human clinical studies reported that sitagliptin had reduced albuminuria in many T2DM patients with nephropathy [39-42]. When sitagliptin was administered, the bigger reduction of urinary albumin was observed in the cases who had the greater albuminuria at the baseline [40]. Based on other reports, administration of sitagliptin in human T2DM patients with nephropathy was followed by the initial drop of eGFR levels, and subsequently, the renal function was stabilized $[43,44]$. Therefore, sitagliptin might have a renal protective effect through ameliorating glomerular hyperfiltration in addition to many renoprotective actions described above.

Finally, the present study demonstrated that changing to a small dose of sitagliptin from other almost full-dose DPP-4 inhibitors before the study reduced the daily drug cost per patient by 88.1 yen. In Japan, the total annual medical cost is estimated to be 40.81 trillion yen in 2014 , out of which 1.22 trillion yen are attributed to patients with diabetes mellitus [45]. Since Japanese Society for Dialysis Therapy evaluated the number of patients requiring dialysis amounting to 324,986 in $2015,38.4 \%$ of which (about 125,000 ) were due to diabetic nephropathy [1], the cost for dialysis is about 5 million yen or more annually, resulting in a total cost of about 1.50 trillion yen or more of total dialysis treatment, and therefore 0.58 trillion yen or more for diabetic patients. Therefore, restraining medical expenses is an important issue. We tried to estimate the medical cost reduction when we changed DPP-4 inhibitors to a small dose of sitagliptin depending on the renal function. It is estimated that 9.5 million individuals in Japan are diabetics, and 2.36 million (24.8\%) of them have decreased renal function with eGFR of less than $60 \mathrm{~mL} / \mathrm{min} / 1.73 \mathrm{~m}^{2}$, requiring a dose adjustment of sitagliptin (excluding patients on dialysis) [46]. By adding 125,000 patients receiving dialysis attributed to diabetic nephropathy, the number of Japanese diabetic patients with decreased renal function has been estimated to be 2.485 million. DPP-4 inhibitors are prescribed to approximately $50 \%$ of T2DM patients, based on the 2013 data in Japan [47]. Thus, $50 \%$ of the 2.485 million Japanese patients with diabetic nephropathy, corresponding to 1.2425 million, are prescribed with DPP-4 inhibitors. Approximately $80 \%$ of patients are prescribed with DPP- 4 inhibitors other than sitagliptin. When other DPP-4 inhibitors are changed to sitagliptin, the drug costs per patient, based on the present study, can be reduced by $88.1 \pm 42.4$ yen daily and 32,157 yen yearly. Therefore, in treating Japanese patients with diabetic nephropathy, switching from other DPP-4 inhibitors to sitagliptin with doses depending on renal function is estimated to reduce the national medical costs by approximately 32 billion yen yearly (the minimum lower 
limit SD is 16.6 billion yen and the maximum upper limit $\mathrm{SD}$ is 47.3 billion yen) as calculated below:

(2 $485000 \times 0.5 \times 0.8 \times 88.1 \times 365=31963561000)$.

(The lower limit SD: $2485000 \times 0.5 \times 0.8 \times 45.7 \times 365$ $=16580417000$ ).

(The upper limit SD: $2485000 \times 0.5 \times 0.8 \times 130.5 \times 365$ $=47346705$ 000).

In T2DM patients with renal dysfunction, sitagliptin, even at a small dose, can be expected to maintain the efficacy and safety and reduce the costs, and thus, it can also be a valid option in reducing the national medical costs in Japan.

\section{Limitations}

Since this study targeted the cases with moderately or severely impaired renal function, cases with normal renal function are not included. The study period was only 6 months, and thus comparative results of the efficacy and safety for a longer period cannot be guaranteed. As the cases in this study were not strictly allocated, the number of patients was not the same between vildagliptin, alogliptin, and linagliptin utilized before the study. Since the study included only six cases that received alogliptin before the study, the results of this subgroup cannot be generalized. Although the index of glycemic control was based on the value of $\mathrm{HbA} 1 \mathrm{c}$ at the entry of this study, but $\mathrm{HbA1c}$ is not often the adequate marker for the patients with renal dysfunction. Glycated albumin was determined in dialysis subjects, but was not measured in non-dialysis subjects. We collected blood samples at 1-2 $\mathrm{h}$ after meals, since the unified meal or the test meal was impossible in real-world clinical trials. However, we asked patients to have the same breakfast as much as possible. The reduction in the medical costs was a rough estimation, and drug cost also varies depending on the countries and/or their insurance system, and therefore, it cannot be referred to countries other than Japan.

\section{Conclusion}

In T2DM patients with moderate to severe renal impairment, switching to a small dose of sitagliptin from other DPP-4 inhibitors resulted in no significant changes in glycemic control and renal function without the adverse events during the 6-month study period. Furthermore, the cost for medicine was substantially reduced. Dose-adjusted sitagliptin depending on renal function offers a cost benefit without reducing the efficacy and safety and would be a useful option to treat diabetic patients with renal dysfunction.

Acknowledgements We would like to express our sincere gratitude to Mr. Shogo Shishikura (MSD K.K.) (Teikyo University Graduate
School of Public Health, MPH) for scientific advice including references for revising the manuscript. We also would like to thank Nouvelle Place Inc. for conducting the data collection and analyses.

Author contribution Conceived and designed the experiments: KK SK. Enrolled patients: KK YN SS SN HY KK RK SK. Analyzed the data: KK SK SS TO HH. Wrote the first draft of the manuscript: KK SK. Contributed to the writing of the manuscript: KK YN SS SN HY KK RK SS TO HH SK. Agree with the manuscript's results and conclusions: KK YN SS SN HY KK RK SS TO HH SK. All authors have read, and confirm that they meet, ICMJE criteria for authorship.

\section{Compliance with ethical standards}

Conflict of interest Shigehiro Katayama and Koichi Kanozawa received honoraria from MSD K.K., Koichi Kanozawa received honoraria from Ono Pharmaceutical Co. Ltd., Hirohisa Yamamoto received honoraria from Yoshindo Inc. and Otsuka Pharmaceutical Co. Ltd. Other authors declare no conflict of interest.

Funding This study was funded by The Waksman Foundation of Japan Inc.

Ethic approval All procedures followed were in accordance with the ethical standards of the responsible committee on human experimentation (institutional and national) and with the Helsinki Declaration of 1964 and later versions. The Institutional Review Board at Saitama Medical University Hospital approved the study (approval number: 13-094-1) on December 10, 2013.

Informed consent Informed consent was obtained from all patients for being included in the study.

Open Access This article is distributed under the terms of the Creative Commons Attribution 4.0 International License (http://creativecommons.org/licenses/by/4.0/), which permits unrestricted use, distribution, and reproduction in any medium, provided you give appropriate credit to the original author(s) and the source, provide a link to the Creative Commons license, and indicate if changes were made.

\section{References}

1. The Japanese Society for Dialysis Therapy. Current status of dialysis therapy. 2015. http://docs.jsdt.or.jp/overview/. Accessed 17 Aug 2017.

2. Bello AK, Levin A, Tonelli M, Okpechi IG, Feehally J, Harris D, Jindal K, Salako BL, Rateb A, Osman MA, Qarni B, Saad S, Lunney M, Wiebe N, Ye F, Johnson DW. Assessment of global kidney health care status. JAMA. 2017;317(18):1864-81.

3. Sakamoto M, Nishimura R, Irako T, Tsujino D, Ando K, Utsunomiya K. Comparison of vildagliptin twice daily vs. sitagliptin once daily using continuous glucose monitoring (CGM): crossover pilot study (J-VICTORIA study). Cardiovasc Diabetol. 2012;11:92.

4. Marfella R, Barbieri M, Grella R, Rizzo MR, Nicoletti GF, Paolisso G. Effects of vildagliptin twice daily vs. sitagliptin once daily on 24-h acute glucose fluctuations. J Diabetes Complicat. 2010;24(2):79-83.

5. Guerci B, Monnier L, Serusclat P, Petit C, Valensi P, Huet D, Raccah D, Colette C, Quéré S, Dejager S. Continuous glucose profiles with vildagliptin versus sitagliptin in add-on to metformin: 
results from the randomized Optima study. Diabetes Metab. 2012;38(4):359-66.

6. Tang YZ, Wang G, Jiang ZH, Yan TT, Chen YJ, Yang M, Meng LL, Zhu YJ, Li CG, Li Z, Yu P, Ni CL. Efficacy and safety of vildagliptin, sitagliptin, and linagliptin as add-on therapy in Chinese patients with T2DM inadequately controlled with dual combination of insulin and traditional oral hypoglycemic agent. Diabetol Metab Syndr. 2015;7:91.

7. Kothny W, Lukashevich V, Foley JE, Rendell MS, Schweizer A. Comparison of vildagliptin and sitagliptin in patients with type 2 diabetes and severe renal impairment: a randomised clinical trial. Diabetologia. 2015;58(9):2020-6.

8. Park SH, Nam JY, Han E, Lee YH, Lee BW, Kim BS, Cha BS, Kim CS, Kang ES. Efficacy of different dipeptidyl peptidase-4 (DPP-4) inhibitors on metabolic parameters in patients with type 2 diabetes undergoing dialysis. Medicine (Baltimore). 2016;95(32):e4543 (online).

9. Mannucci E, Ognibene A, Cremasco F, Bardini G, Mencucci A, Pierazzuoli E, Ciani S, Messeri G, Rotella CM. Effect of metformin on glucagon-like peptide 1 (GLP-1) and leptin levels in obese nondiabetic subjects. Diabetes Care. 2001;24(3):489- 94.

10. Inaba M, Okuno S, Kumeda Y, Yamada S, Imanishi Y, Tabata T, Okamura M, Okada S, Yamakawa T, Ishimura E, Nishizawa Y, Osaka. CKD Expert Research Group. Glycated albumin is a better glycemic indicator than glycated hemoglobin values in hemodialysis patients with diabetes: effect of anemia and erythropoietin injection. J Am Soc Nephrol. 2007;18(3):896-903.

11. Arjona Ferreira JC, Marre M, Barzilai N, Guo H, Golm GT, Sisk CM, Kaufman KD, Goldstein BJ. Efficacy and safety of sitagliptin versus glipizide in patients with type 2 diabetes and moderate-to-severe chronic renal insufficiency. Diabetes Care. 2013;36(5):1067-73.

12. Chan JC, Scott R, Arjona Ferreira JC, Sheng D, Gonzalez E, Davies MJ, Stein PP, Kaufman KD, Amatruda JM, WilliamsHerman D. Safety and efficacy of sitagliptin in patients with type 2 diabetes and chronic renal insufficiency. Diabetes Obes Metab. 2008;10(7):545-55.

13. Arjona Ferreira JC, Corry D, Mogensen CE, Sloan L, Xu L, Golm GT, Gonzalez EJ, Davies MJ, Kaufman KD, Goldstein BJ. Efficacy and safety of sitagliptin in patients with type 2 diabetes and ESRD receiving dialysis: a 54-week randomized trial. Am J Kidney Dis. 2013;61(4):579-87.

14. Maeda H, Kubota A, Kanamori A, Tanaka Y, Terauchi Y, Matsuba I. Study Group of Diabetes Committee, Kanagawa Physicians Association. Effects of sitagliptin on the serum creatinine in Japanese type 2 diabetes. Diabetes Res Clin Pract. 2015;108(3):e42-e5.

15. Cornel JH, Bakris GL, Stevens SR, Alvarsson M, Bax WA, Chuang LM, Engel SS, Lopes RD, McGuire DK, Riefflin A, Rodbard HW, Sinay I, Tankova T, Wainstein J, Peterson ED, Holman RR. TECOS Study Group. Effect of sitagliptin on kidney function and respective cardiovascular outcomes in type 2 diabetes: outcomes from TECOS. Diabetes Care 2016;39(12):2304-10.

16. Wada T, Shimizu M, Yokoyama H, Iwata Y, Sakai Y, Kaneko S, Furuichi K. Nodular lesions and mesangiolysis in diabetic nephropathy. Clin Exp Nephrol. 2013;17(1):3-9.

17. Araki S, Matsuno H, Haneda M, Koya D, Kanno Y, Kume S, Isshiki K, Araki H, Ugi S, Kawai H, Kashiwagi A, Uzu T, Maegawa $\mathrm{H}$. Cilostazol attenuates spontaneous microaggregation of platelets in type 2 diabetic patients with insufficient platelet response to aspirin. Diabetes Care. 2013;36(7):1248-53.

18. Hayashi Y, Makino H, Ota Z. Serum and urinary concentrations of type IV collagen and laminin as a marker of microangiopathy in diabetes. Diabetes Med. 1992;9(4):366 - 70.
19. Uzun S, Ozari M, Gursu M, Karadag S, Behlul A, Sari S, Koldas M, Demir S, Karaali Z, Ozturk S. Changes in the inflammatory markers with advancing stages of diabetic nephropathy and the role of pentraxin-3. Ren Fail. 2016;38(8):1193-8.

20. Hocher B, Reichetzeder C, Alter ML. Renal and cardiac effects DPP-4 inhibitors - from preclinical development to clinical research. Kidney Blood Press Res. 2012;36(1):65-84.

21. Gutzwiller JP, Hruz P, Huber AR, Hamel C, Zehnder C, Drewe J, Gutmann H, Stanga Z, Vogel D, Beglinger C. Glucagon-like peptide-1 is involved in sodium and water homeostasis in humans. Digestion. 2006;73(2-3):142-50.

22. Hirata K, Kume S, Araki S, Sakaguchi M, Chin-Kanasaki M, Isshiki K, Sugimoto T, Nishiyama A, Koya D, Haneda M, Kashiwagi A, Uzu T. Exendin-4 has an anti-hypertensive effect in salt-sensitive mice model. Biochem Biophys Res Commun. 2009;380(1):44-9.

23. Carraro-Lacroix LR, Malnic G, Girardi AC. Regulation of $\mathrm{Na}^{+} /$ $\mathrm{H}^{+}$exchanger NHE3 by glucagon-like peptide 1 receptor agonist exendin-4 in renal proximal tubule cells. Am J Physiol Ren Physiol. 2009;297(6):F1647-F55.

24. Rieg T, Gerasimova M, Murray F, Masuda T, Tang T, Rose M, Drucker DJ, Vallon V. Natriuretic effect by exendin-4, but not the DPP-4 inhibitor alogliptin, is mediated via the GLP-1 receptor and preserved in obese type 2 diabetic mice. Am J Physiol Ren Physiol. 2012;303(7):F963-F71.

25. Mima A, Hiraoka-Yamomoto J, Li Q, Kitada M, Li C, Geraldes P, Matsumoto M, Mizutani K, Park K, Cahill C, Nishikawa S, RaskMadsen C, King GL. Protective effects of GLP-1 on glomerular endothelium and its inhibition by PKC $\beta$ activation in diabetes. Diabetes. 2012;61(11):2967-79.

26. Kodera R, Shikata K, Kataoka HU, Takatsuka T, Miyamoto S, Sasaki M, Kajitani N, Nishishita S, Sarai K, Hirota D, Sato C, Ogawa D, Makino H. Glucagon-like peptide-1 receptor agonist ameliorates renal injury through its anti-inflammatory action without lowering blood glucose level in a rat model of type 1 diabetes. Diabetologia. 2011;54(4):965-78.

27. Ishibashi Y, Matsui T, Ojima A, Nishino Y, Nakashima S, Maeda S, Yamagishi S. Glucagon-like peptide-1 inhibits angiotensin IIinduced mesangial cell damage via protein kinase A. Microvasc Res. 2012;84(3):395-8.

28. Park CW, Kim HW, Ko SH, Lim JH, Ryu GR, Chung HW, Han SW, Shin SJ, Bang BK, Breyer MD, Chang YS. Long-term treatment of glucagon-like peptide-1 analog exendin-4 ameliorates diabetic nephropathy through improving metabolic anomalies in $\mathrm{db} / \mathrm{db}$ mice. J Am Soc Nephrol. 2007;18(4):1227-38.

29. Fujita H, Morii T, Fujishima H, Sato T, Shimizu T, Hosoba M, Tsukiyama K, Narita T, Takahashi T, Drucker DJ, Seino Y, Yamada Y. The protective roles of GLP-1R signaling in diabetic nephropathy: possible mechanism and therapeutic potential. Kidney Int. 2014;85(3):579-89.

30. Marso SP, Daniels GH, Brown-Frandsen K, Kristensen P, Mann JF, Nauck MA, Nissen SE, Pocock S, Poulter NR, Ravn LS, Steinberg WM, Stockner M, Zinman B, Bergenstal RM, Buse JB, LEADER Steering Committee, LEADER Trial Investigators. Liraglutide and cardiovascular outcomes in type 2 diabetes. $\mathrm{N}$ Engl J Med. 2016;375(4):311-22.

31. Marso SP, Bain SC, Consoli A, Eliaschewitz FG, Jódar E, Leiter LA, Lingvay I, Rosenstock J, Seufert J, Warren ML, Woo V, Hansen O, Holst AG, Pettersson J, Vilsbøll T, SUSTAIN-6 Investigators. Semaglutide and cardiovascular outcomes in patients with type 2 diabetes. N Engl J Med. 2016;375(19):1834-44.

32. Marques C, Mega C, Gonçalves A, Rodrigues-Santos P, Teixeira-Lemos E, Teixeira F, Fontes-Ribeiro C, Reis F, Fernandes R. Sitagliptin prevents inflammation and apoptotic cell death 
in the kidney of type 2 diabetic animals. Mediat Inflamm. 2014;2014:538737. (online).

33. Muskiet MH, Smits MM, Morsink LM, Diamant M. The gut-renal axis: do incretin-based agents confer renoprotection in diabetes? Nat Rev Nephrol. 2014;10(2):88-103.

34. Aroor AR, Sowers JR, Jia G, DeMarco VG. Pleiotropic effects of the dipeptidylpeptidase-4 inhibitors on the cardiovascular system. Am J Physiol Heart Circ Physiol. 2014;307(4):H477-H92.

35. Girardi AC, Fukuda LE, Rossoni LV, Malnic G, Rebouças NA. Dipeptidyl peptidase IV inhibition downregulates $\mathrm{Na}^{+}-\mathrm{H}^{+}$ exchanger NHE3 in rat renal proximal tubule. Am J Physiol Ren Physiol. 2008;294(2):F414-F22.

36. Lovshin JA, Rajasekeran H, Lytvyn Y, Lovblom LE, Khan S, Alemu R, Locke A, Lai V, He H, Hittle L, Wang W, Drucker DJ, Cherney DZI. Dipeptidyl peptidase-4 inhibition stimulates distal tubular natriuresis and increases in circulating SDF-1 $\alpha(1-67)$ in patients with type 2 diabetes. Diabetes Care. 2017. https://doi. org/10.2337/dc17-0061. (online).

37. Kim M, Platt MJ, Shibasaki T, Quaggin SE, Backx PH, Seino S, Simpson JA, Drucker DJ. GLP-1 receptor activation and Epac2 link atrial natriuretic peptide secretion to control of blood pressure. Nat Med. 2013;19(5):567-75.

38. Kanasaki K, Shi S, Kanasaki M, He J, Nagai T, Nakamura Y, Ishigaki Y, Kitada M, Srivastava SP, Koya D. Linagliptin-mediated DPP-4 inhibition ameliorates kidney fibrosis in streptozotocininduced diabetic mice by inhibiting endothelial-to-mesenchymal transition in a therapeutic regimen. Diabetes. 2014;63:2120-31.

39. Hattori S. Sitagliptin reduces albuminuria in patients with type 2 diabetes. Endocr J. 2011;58(1):69-73.

40. Kawasaki I, Hiura Y, Tamai A, Yoshida Y, Yakusiji Y, Ikuno Y, Okada M, Ueno H, Tanaka N, Yamagami K, Fukumoto M, Hosoi $\mathrm{M}$. Sitagliptin reduces the urine albumin-to-creatinine ratio in type 2 diabetes through decreasing both blood pressure and estimated glomerular filtration rate. J Diabetes. 2015;7(1):41-6.

41. Mori H, Okada Y, Arao T, Tanaka Y. Sitagliptin improves albuminuria in patients with type 2 diabetes mellitus. J Diabetes Investig. 2014;5(3):313-9.
42. Goldshtein I, Karasik A, Melzer-Cohen C, Engel SS, Yu S, Sharon O, Brodovicz K, Gadir N, Katzeff HL, Radican L, Chodick G, Shalev V, Tunceli K. Urinary albumin excretion with sitagliptin compared to sulfonylurea as add on to metformin in type 2 diabetes patients with albuminuria: a real-world evidence study. $\mathrm{J}$ Diabetes Complicat. 2016;30(7):1354-59.

43. Yuasa S, Sato K, Takai M, Ishikawa M, Umezawa S, Kubota A, Maeda H, Kanamori A, Miyakawa M, Tanaka Y, Terauchi Y, Matsuba I. Factor analysis of changes in hemoglobin A1c after 12 months of sitagliptin therapy in patients with type 2 diabetes. J Clin Med Res. 2016;8(6):461-71.

44. Tonneijck L, Smits MM, Muskiet MH, Hoekstra T, Kramer MH, Danser AH, Ter Wee PM, Diamant M, Joles JA, van Raalte DH. Renal effects of DPP-4 inhibitor sitagliptin or GLP-1 receptor agonist liraglutide in overweight patients with type 2 diabetes: a 12-week, randomized, double-blind, placebo-controlled trial. Diabetes Care. 2016;39(11):2042-50.

45. Ministry of Health, Labour and Welfare, Japan. Estimates of national medical care expenditure. 2014 http://www.mhlw.go.jp/ toukei/saikin/hw/k-iryohi/14/dl/data.pdf. Accessed 17 Aug 2017.

46. Wada T, Haneda M, Furuichi K, Babazono T, Yokoyama H, Iseki K, Araki S, Ninomiya T, Hara S, Suzuki Y, Iwano M, Kusano E, Moriya T, Satoh H, Nakamura H, Shimizu M, Toyama T, Hara A, Makino H, Research Group of Diabetic Nephropathy, Ministry of Health, Labour, and Welfare of Japan. Clinical impact of albuminuria and glomerular filtration rate on renal and cardiovascular events, and all-cause mortality in Japanese patients with type 2 diabetes. Clin Exp Nephrol. 2014;18(4):613-20.

47. Hidaka H, Tokumoto K, Hori Y, Homma S, Inoue C. Prescription and quality of diabetes care provided by specialists and general physicians in Japan - an analysis of insurance claim and health checkup data. J Jpn Diab Soc. 2014;57(10):774-82. 